\title{
Transforming the students community into a social network
}

\author{
José Luis Poy ${ }^{1}$, Joan Lasierra ${ }^{2}$ \\ ${ }^{1}$ SIGMA Gestión Universitaria, Alcalde Barnils 64-68 08174 Sant Cugat Barcelona, \\ jose.luis.poy@sigmaaie.org \\ ${ }^{2}$ SIGMA Gestión Universitaria, Alcalde Barnils 64-68 08174 Sant Cugat Barcelona, \\ joan.lasierra@sigmaaie.org
}

\section{Keywords}

Social networking, University community, Student Information System, eLearning, Mobile App, Personal relationships.

\section{ABSTRACT}

Technology and Innovation are the backbone of the services and solutions provided by SIGMA, based on a highly open source development and deployment platform for J2EE5 certified application servers compliant on a multi-tier and high performance proven open architecture. Internationalization is one of SIGMA's top priorities, as well. For years SIGMA has established relationships with other European universities consortiums. Lately SIGMA has open new strategic areas of interest such as SaaS, BI, eLearning and Mobile. SIGMA focuses the development and support of two main suites of solutions: VEGA Student Information System and ARGOS Research Information System.

Social networking is a phenomenon spread across all layers of society. The university community should be noted for its dynamism and modernity and, therefore, it is logical to think that it is an appropriate setting for the emergence of different groups of people interacting who can make use of social networks for their intercommunication and collaboration.

This mobile App, Pizarra, aims to make the most of the university community through the existing information structures and platforms to provide a communication channel for community members that is split from teaching and learning but can extend its use to personal relationships between students and teachers.

\section{TRANSFORMING THE STUDENTS COMMUNITY INTO A SOCIAL NETWORK}

Social networking is a phenomenon spread across all layers of society. The university community should be noted for its dynamism and modernity and, therefore, it is logical to think that it is an appropriate setting for the emergence of different groups of people interacting who can make use of social networks for their intercommunication and collaboration.

An added value that can be obtained from a Student Information System is an existing structure and predefined relationships for their own activity. Students and teachers are grouped around a backbone formed by the university, different campuses, schools and faculties, syllabi, courses and class groups.

The relationships between teachers and students are often supported by eLearning platforms. In a class group you can find peers who share not only a physical or virtual location, but the need to solve common questions for their learning plan. Basically, the students must be able to communicate with their peers and with the teacher, must be able to access the resources of the courses, share a calendar of events and finally see their grades. The same applies to the teacher.

As dealing with separate systems, some mechanisms have to be provided to integrate information from Student Information Systems (oriented to academic management) and eLearning platforms (oriented to teaching). This integration, often carried out in a homemade way, gives a powerful set of people, information and resources to put them together and provide services to the community. 
Facebook, Tweeter or WhatsApp are applications used by millions of people. People who communicate in such networks have different self-defined relationships whether personal or professional. The advantage of pooling information from a Student Information System and an eLearning platform using a mobile device is that a number of groups within the community can be created automatically at the opening of the academic year from the information defined during enrollment.

The students are required to enroll but they have vested interest in the results of their studies. Thus, the first feature that is made available to a student on his mobile device is to obtain the final grade for a course that has just been completed. From there, through a strategy of iterative upgrades of functionality, other information related to his/her file is added, and finally, the ability to start sharing messages between members of the group, with the teacher, in small groups, open, etc.

SIGMA provides to the community a full integration between VEGA Student Information System and the university Moodle/Sakai eLearning platform. In 2012 SIGMA has developed and set up a native application for the most popular used mobile systems, Android and iOS, called Pizarra.

On the basis of the feature that allows the students to see their grades online and in real time accessing the eLearning platform information, Pizarra enables the teacher to send messages to the class group members (students and other teachers), who receive notifications of new posts on their mobile devices.

Additionally, the teacher has a web version integrated in Moodle with the same functionality, so that from the eLearning platform he can send messages to the Pizarra App used by the students in his class group.

Moreover, Pizarra allows students to send messages to class group members (including the teacher), and all members to comment the messages in conversation mode as a blog.

Pizarra provides functionality which starts to generate a social network concept at the moment that allows users to create their own groups, different from automatically defined class groups, to share their messages on Twitter and Facebook and to create an easily accessible channel for the analysis of feedback on user experience and / or using tools such as Google Analytics.

Pizarra is still under development and in Summer 2013 will release new versions that will incorporate features to allow users to attach files to messages, to define favorite Meeting Points (Cafeteria, Lawn, Library, etc.) and to send one-click messages to "my colleagues" to meet in those places.

To integrate uploading and downloading notes and material in shared spaces, as DropBox or Google Docs, for "my colleagues" to see (not necessarily related to the course), complementing the shared space in the elearning platform, will be a new feature too.

Once the community is established, the university will be able to use the new network with web functionality Virtual Bulletin Board, from which faculties could send institutional messages to the community groups, who will receive them again in the Pizarra using their mobile devices.

This mobile App, Pizarra, aims to make the most of the university community through the existing information structures and platforms to provide a communication channel for community members that is split from teaching and learning but can extend its use to personal relationships between students and teachers.

\section{REFERENCES}

ABC website (2012). ABC Digital Newspaper. Retrieved December 3, 2012 from: http://www.abc.es/local-castilla-leon/20121203/abci-pizarra-whatssap-201212031435.Html

"Pizarra is a native App for mobile devices that has been called the University of Valladolid's WhatsApp." 


\section{AUTHORS}

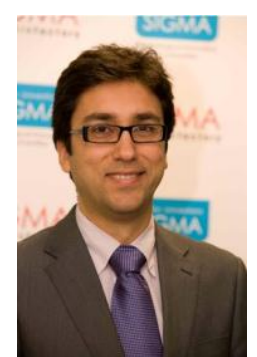

Jose Luis Poy, CTO Chief Technology \& Innovation Officer

MBA at Universitat Politècnica de Catalunya (2005 - 2006),

Postgraduate in Information Systems Manager at Universitat Politècnica de Catalunya (2004 - 2005),

Postgraduate in Production Manager at Institut Català de Tecnologia (2003 - 2003),

Computer and Software Engineer at Universitat Autònoma de Barcelona (1985 1991).

He works for SIGMA since 1994, covering different technical and managerial roles. He has been the COO Chief Operations Officer for the SIGMA's 2008-2012 Transformation Plan, managing a 100 people Software Engineering team, with activity areas in Product, Service and Market Strategy, Annual Budget for incomes and costs, Organization, Quality and Methodology, Internationalization, Full Product Life Cycle (PreSales, Execution,PostSales (Project, Product, Service), Project and Resources Management, Software Factory, J2EE Platform, Out of The Box Implantation \& SaaS, Customer Service continuous improvement, Help Desk \& SLA). As CTO, his main current activity is related to innovation and technology, with special interest areas as Mobile Apps, BI platforms, eLearning platforms and Cloud services. He is a member of RS3G, group in which works to facilitate the European Student Mobility, and he is also a member of EuroCRIS, organization in which deals with Research Information Systems standards.

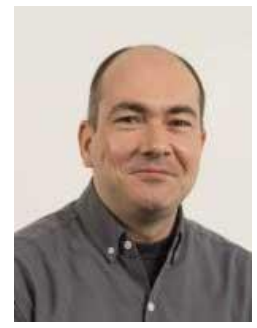

Joan Lasierra, Lead Mobile SIGMA Software Engineer

Technical Engineering in Computer Management at UOC

Seventeen years experience analyzing, developing and troubleshooting software and systems architecture. Since 2011 he directs the newly created Mobile Apps team at Sigma which has published several applications targeting the university community, mainly applications for iPhone / iPad and Android, as well as hybrid applications and mobile web apps (HTML5). 